\section{Influencia de la ganancia de peso durante el primer año del trasplante renal en la sobrevida de injertos y pacientes}

\author{
JORGE VEGA ${ }^{1,2,3}$, JUAN PABLO HUIDOBRO E. ${ }^{3}$, \\ SOFÍA DE LA BARRA ${ }^{\mathrm{a}}$, DANISSA HARO ${ }^{\mathrm{a}}$
}

\section{Influence of weight gain during the first year after kidney transplantation in the survival of grafts and patients}

Background: After receiving a kidney allograft, patients tend to gain weight acquiring the risk associated with overweight and obesity. Aim: To compare the evolution during 10 years after transplantation of patients who gained more than $15 \%$ of their initial weight during the first year after receiving the graft with those who did not experience this increase. Material and Methods: Cohort study of 182 patients transplanted in a single hospital between 1981 and 2003. Demographic data, weight gain during the first year, drugs used, complications and evolution of patients and grafts were recorded. Results: Seventy two patients gained more than $15 \%$ of their weight during the first year. These were discharged after receiving the graft with a lower serum creatinine than their counterparts (1.46 \pm 0.71 and $1.97 \pm 1.74 \mathrm{mg} / \mathrm{dl}$ respectively, $p=0.02)$. Ten years mortality with a functioning kidney was higher among weight gainers (25 and $12.7 \%$ respectively, $p=0.03$ ). No other differences were observed between groups. Conclusions: Patients who gained more than 15\% of their initial weight during the first year after receiving a kidney graft have a higher 10 years mortality with a functioning kidney.

(Rev Med Chile 2015; 143: 961-970)

Key words: Kidney transplantation; Metabolic syndrome X; Mortality; Obesity; Postoperative complications; Treatment outcome.

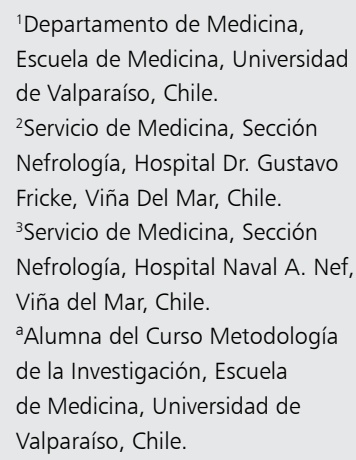

Recibido el 24 de febrero de 2015, aceptado el 15 de junio de 2015 .

Correspondencia a:

Jorge Vega

5 Norte 1035, Viña del Mar,

Chile.

Teléfono: 56-32-2974237

jvegastieb@gmail.com

\section{L} a obesidad constituye un factor de riesgo para la salud y ha sido asociada con una mayor mortalidad en la población general ${ }^{1}$. En las últimas décadas la prevalencia de obesidad ha ido aumentando rápidamente, tanto en países desarrollados como en desarrollo, adoptando características de una verdadera epidemia ${ }^{2}$. En la ganancia de peso participan el género, la edad, factores genéticos, ejercicio, nivel socioeconómico, raza, hábitos dietéticos y estado de salud ${ }^{3}$.

En la población de pacientes con enfermedad renal crónica, la epidemia de obesidad no ha sido una excepción, comunicándose que alrededor de $60 \%$ de los enfermos al momento del trasplante renal (TxR) tienen sobrepeso u obesidad ${ }^{4}$.

En los pacientes trasplantados renales existen otros factores adicionales que favorecen la ganancia de peso, como los efectos de las drogas inmunosupresoras y corticoides (que aumentan la grasa corporal y originan retención de líquido), reducción de la actividad física en los primeros meses del TxR, aumento del apetito y en la sensación de 
bienestar general, desaparición de las restricciones dietéticas impuestas durante el período dialítico ${ }^{5-8}$.

Numerosos centros de trasplantes ponen limitaciones a los pacientes obesos para ingresar a programas de TxR por temor a una alta tasa de complicaciones peri-operatorias y a una menor sobrevida de pacientes de injertos 9 . Estos resultados han sido comunicados en numerosos trabajos ${ }^{10-20}$, sin embargo, también hay publicaciones que no han mostrado diferencias en la evolución de los TxR efectuados en pacientes con sobrepeso $u$ obesidad respecto a sujetos con IMC normal ${ }^{9,21-25}$. Como el efecto del sobrepeso y la obesidad previo al trasplante no está claro en la evolución de los pacientes o sus injertos, por razones éticas se ha sugerido incluir a estos enfermos en los programas de trasplante renal, al igual como se incluye a pacientes diabéticos o añosos, los que categóricamente tienen una menor sobrevida ${ }^{26}$.

La información comunicada sobre el efecto de la ganancia significativa de peso posterior al trasplante es escasa y sugiere que se asocia a una menor sobrevida de injertos y pacientes a corto y largo plazo ${ }^{27-31}$.

El objetivo de este trabajo fue conocer si la ganancia significativa de peso $(\geq 15 \%)$ durante el primer año del TxR influye sobre la incidencia de complicaciones y la sobrevida de pacientes e injertos en los primeros 10 años del TxR.

\section{Sujetos y Método}

De 254 pacientes trasplantados de riñón entre 1981 y 2003 en el Hospital Dr. Gustavo Fricke de Viña del Mar, se seleccionaron los TxR efectuados en pacientes de $\geq 18$ años, que estaban funcionantes al año de la intervención y que el intervalo transcurrido entre el trasplante y la fecha de corte (diciembre de 2014) no fuera inferior a los 10 años. Se excluyó a 72 pacientes. Las razones de la exclusión fueron: el haber recibido previamente un trasplante renal que funcionó adecuadamente durante un tiempo, el haber incrementado el peso durante el primer año secundariamente a un embarazo o un síndrome edematoso y el no haber contado con información suficiente.

Ciento ochenta y dos pacientes cumplieron los criterios de inclusión y de ellos se registraron: datos demográficos e inmunológicos, antecedentes de la etapa previa al TxR, peso al primer control ambulatorio después del trasplante y al duodécimo mes; complicaciones durante los primeros 10 años de seguimiento, terapia inmunosupresora empleada durante la evolución, función renal durante los 10 años de seguimiento, estado del paciente e injerto a la fecha de corte y las causas de muerte en los que fallecieron con un riñón funcionante.

Se utilizó la base de datos electrónica existente en la Unidad de Trasplante Renal.

La velocidad de filtración glomerular se estimó con la fórmula MDRD.

Los pacientes se separaron en dos grupos, dependiendo si su incremento de peso al año respecto al del primer control ambulatorio fue $<15 \%$ (Grupo 0) o $\geq 15 \%$ (Grupo 1).

Para las variables cualitativas se utilizó frecuencias y porcentajes y para su análisis las pruebas del $\chi^{2}$ y test exacto de Fisher. Para las variables cuantitativas se utilizó medianas, rango intercuartil, promedios y desviación estándar y para el análisis las pruebas de $t$ de Student y Wilcoxon. Para la confección de curvas de sobrevida de empleó el método de Kaplan-Meir. Se consideró significativo un valor de $\mathrm{p}<0,05$.

\section{Resultados}

Los pacientes que tuvieron un incremento de peso $\geq$ a $15 \%$ durante el primer año de trasplante, no difirieron de los que no modificaron su peso en dicha magnitud en edad ni género y tampoco lo hicieron respecto al tipo, género o edad del donante (Tabla 1).

El tiempo de permanencia en diálisis previo al TxR y la prevalencia de diabetes mellitus o infección por los virus de la hepatitis B o C no fue significativamente diferente entre ambos grupos (Tabla 1).

La compatibilidad en los antígenos de histocompatibilidad HLA de clase 1 y 2 , así como la tasa de anticuerpos contra linfocitos de panel (PRA) histórico (máximo) y previo al TxR fue similar entre ambos grupos (Tabla 1).

Al momento del alta del hospital después del TxR, los que incrementaron su peso $\geq 15 \%$ al año del TxR egresaron con una creatinina plasmática significativamente inferior a la de los que no incrementaron su peso al año en $\geq 15 \%$ (1,46 vs $1,97 \mathrm{mg} / \mathrm{dl} ; \mathrm{p}=0,02)$. Sin embargo, la velocidad de filtración glomerular estimada al año 1, 5 y 10 del TxR fue similar entre ambos grupos (Tabla 2). 
Tabla 1. Características demográficas e inmunológicas en 182 trasplantados renales

\begin{tabular}{|lccc|}
\hline & $\begin{array}{c}\text { Grupo 0 } \\
(\mathbf{n = 1 1 0})\end{array}$ & $\begin{array}{c}\text { Grupo 1 } \\
(\mathbf{n = 7 2 )}\end{array}$ & p \\
\hline Edad receptor (años) media (DS) & $38,3(11,6)$ & $39,0(11,6)$ & NS \\
\hline Sexo receptor (\% masculino) & 58,1 & 55,6 & NS \\
\hline Donante fallecido n (\%) & $66(60)$ & $31(43)$ & NS \\
\hline Donante vivo n (\%) & $44(40)$ & $41(57)$ & NS \\
\hline Edad donante (años) media (DS) & $36,4(13,4)$ & $32,5(12,4)$ & NS \\
\hline Sexo donante (\% masculino) & 53,2 & 57,1 & NS \\
\hline Permanencia en HDC (meses) media (DS) & $36,5(31,7)$ & $26,8(34,6)$ & NS \\
\hline Diabetes mellitus previa al TxR n (\%) & $3(2,8)$ & $5(6,9)$ & NS \\
\hline Infección por virus B hepatitis n (\%) & $3(2,9)$ & $3(4,2)$ & NS \\
\hline Infección por virus C hepatitis n (\%) & $19(23,7)$ & $11(28,2)$ & NS \\
\hline Incompatibilidades Antígenos HLA A,B media (DS) & $1,9(1,0)$ & $1,6(0,9)$ & NS \\
\hline Incompatibilidades Antígenos HLA DR media (DS) & $0,5(0,6)$ & $0,6(0,5)$ & NS \\
\hline PRA (\%) previo al TxR media (DS) & $4,1(8,5)$ & $6,2(15,2)$ & NS \\
\hline PRA (\%) máximo media (DS) & $11,4(17,7)$ & $12,5(18,8)$ & NS \\
\hline
\end{tabular}

HDC: hemodiálisis crónica; HLA: antígenos de histocompatibilidad; PRA: porcentaje de anticuerpos reactivos contra un panel de linfocitos.

Tabla 2. Evolución del injerto renal durante los primeros 10 años del trasplante

\begin{tabular}{|c|c|c|c|}
\hline & $\begin{array}{c}\text { Grupo } 0 \\
(n=110)\end{array}$ & $\begin{array}{l}\text { Grupo } 1 \\
(n=72)\end{array}$ & $\mathbf{p}$ \\
\hline Creatininemia (mg/dl) al alta media (DS) & $1,97(1,74)$ & $1,46(0,71)$ & 0,02 \\
\hline eVFG al año del TxR media (DS) (ml/min/1,73m²) & $68(35)$ & $75(35)$ & NS \\
\hline eVFG al año 5 del TxR media (DS) (ml/min/1,73m²) & $53(16)$ & $65(36)$ & NS \\
\hline eVFG al año 10 del TxR media (DS) (ml/min/1,73m²) & $45(17)$ & $47(17)$ & NS \\
\hline Regresaron a HDC antes de 10 años del TxR n (\%) & $22(20)$ & $9(12,5)$ & NS \\
\hline Fallecieron con un injerto funcionante antes de los 10 años n (\%) & $14(12,7)$ & $18(25)$ & 0,03 \\
\hline
\end{tabular}

eVFG: velocidad de filtración glomerular estimada; TxR: trasplante renal; HDC: hemodiálisis crónica.

La proporción de trasplantados que recibió terapia anti-rechazo agudo en los primeros 5 años fue similar entre ambos grupos (Tabla 3). La dosis de corticoides e inmunosupresores utilizada durante el primer año del TxR fue similar entre ambos grupos de pacientes y no hubo diferencias en la proporción de pacientes que requirieron una modificación en su terapia inmunosupresora durante los primeros 10 años (Tabla 4).

El porcentaje de pacientes que sufrieron una función retardada del injerto, reoperaciones $\mathrm{u}$ hospitalizaciones durante el primer año del TxR no fue diferente entre los grupos. En los 9 años siguientes, la frecuencia de complicaciones tampoco fue diferente. Cerca de $40 \%$ de los pacientes de ambos grupos requirieron una biopsia renal durante los primeros 10 años del TxR. No hubo diferencias en la prevalencia de hematuria microscópica o proteinuria durante los primeros 3 años del TxR (Tabla 5). 
Tabla 3. Drogas utilizadas durante el primer año del trasplante renal

\begin{tabular}{|c|c|c|c|}
\hline & $\begin{array}{c}\text { Grupo } 0 \\
(n=110)\end{array}$ & $\begin{array}{l}\text { Grupo } 1 \\
(n=72)\end{array}$ & $\mathbf{p}$ \\
\hline Prednisona (mg/kg/día) utilizada al 1er control ambulatorio media (DS) & $0,65(1,2)$ & $0,67(0,2)$ & NS \\
\hline Prednisona (mg/kg/día) utilizada al sexto mes del TxR media (DS) & $0,18(0,1)$ & $0,18(0,8)$ & NS \\
\hline Prednisona (mg/kg/día) utilizada al año del TxR media (DS) & $0,16(0,1)$ & $0,15(0,1)$ & NS \\
\hline Metilprednisolona (g) utilizada durante el 1 1 er año del TxR media (DS) & $0,96(1,5)$ & $1,1(1,7)$ & NS \\
\hline Azatioprina (mg/kg/día) utilizada al 1er control ambulatorio media (DS) & $1,96(0,65)$ & $2,1(1,0)$ & NS \\
\hline Azatioprina (mg/kg/día) utilizada al sexto mes del TxR media (DS) & $1,75(0,62)$ & $1,82(0,58)$ & NS \\
\hline Azatioprina (mg/kg/día) utilizada al año del TxR media (DS) & $1,70(0,63)$ & $1,78(0,57)$ & NS \\
\hline Ciclosporina (mg/kg/día) utilizada al 1 er control ambulatorio media (DS) & $4,3(3,6)$ & $3,5(3,3)$ & NS \\
\hline Ciclosporina (mg/kg/día) utilizada al sexto mes del TxR media (DS) & $1,1(0,9)$ & $1,2(1,3)$ & NS \\
\hline Ciclosporina (mg/kg/día) utilizada año del TxR media (DS) & $1,1(1,0)$ & $0,8(0,7)$ & NS \\
\hline Terapia anti rechazo post-operatoria con corticoides n (\%) & $17(15,7)$ & $18(23,3)$ & NS \\
\hline Terapia anti rechazo durante primer año del TxR con corticoides n (\%) & $30(27,3)$ & $19(26,4)$ & NS \\
\hline Terapia anti rechazo durante primer año del TxR con anticuerpos $n(\%)$ & $5(4,6)$ & $2(2,8)$ & NS \\
\hline Uso de IECA o ARA II al año del TxR n (\%) & $9(8,4)$ & $7(10,3)$ & NS \\
\hline Usan AZA-CsA-PDN al año del TxR n (\%) & $66(60)$ & $38(53)$ & NS \\
\hline Usan AZA-PDN al año del TxR n (\%) & $22(20)$ & $23(31,9)$ & NS \\
\hline Usan CsA-PDN al año del TxR n (\%) & $9(8,2)$ & $10(13,9)$ & NS \\
\hline Usan MMF-CsA-PDN n (\%) & $10(9,0)$ & $0(0)$ & NS \\
\hline Cambio de esquema inmunosupresor durante primer año del TxR n (\%) & $21(19,0)$ & $12(16,7)$ & NS \\
\hline
\end{tabular}

IECA: inhibidores de la enzima de conversión de la angiotensina; ARA II: bloqueadores de los receptores de la angiotensina II; AZA: azatioprina; CsA: ciclosporina; PDN: prednisona; MMF: micofenolato.

Tabla 4. Terapia utilizada después del primer año del trasplante renal

\begin{tabular}{|lccc|}
\hline & $\begin{array}{c}\text { Grupo 0 } \\
\text { (n= 110) }\end{array}$ & $\begin{array}{l}\text { Grupo 1 } \\
\text { (n= 72) }\end{array}$ & p \\
\hline Terapia anti rechazo con corticoides años 2-5 n (\%) & $18(16,5)$ & $18(25,0)$ & NS \\
\hline Metilprednisolona (g) utilizada años 2-3 del TxR media (DS) & $0,35(1,0)$ & $1,37(0,57)$ & NS \\
\hline Cambio en esquema inmunosupresor durante los 10 años del TxR n (\%) & $61(55,4)$ & $32(44,4)$ & NS \\
\hline
\end{tabular}

TxR: trasplante renal.

Durante los primeros 10 años del TxR, la proporción de pacientes que regresaron a diálisis crónica por pérdida de la función del injerto no fue significativamente diferente entre ambos grupos. Sin embargo, la proporción de pacientes que falleció con un injerto renal funcionante antes de cumplir los 10 años de seguimiento fue significativamente superior en los que incrementaron su peso $\geq 15 \%$ durante el primer año del TxR (25\% vs $12,7 \%$; p $=0,03$ ) (Figuras 1 y 2 ). Las causas de muerte con riñón funcionante fueron: infecciones, neoplasias malignas, enfermedades cardiovasculares y trastornos digestivos. No hubo diferencias entre los grupos según la causa del fallecimiento (Tabla 6). 
Tabla 5. Complicaciones durante los primeros 10 años del trasplante renal

\begin{tabular}{|c|c|c|c|}
\hline & $\begin{array}{c}\text { Grupo } 0 \\
(n=110)\end{array}$ & $\begin{array}{l}\text { Grupo } 1 \\
(n=72)\end{array}$ & $\mathbf{p}$ \\
\hline Función renal retardada n (\%) & $18(16,8)$ & $18(25,3)$ & NS \\
\hline Reoperación en postoperatorio n (\%) & $11(10,1)$ & $5(6,9)$ & NS \\
\hline Reoperación en año 1 del TxR n (\%) & $9(8,2)$ & $2(2,8)$ & NS \\
\hline Biopsia renal durante año 1 del TxR n (\%) & $22(20,0)$ & $9(12,5)$ & NS \\
\hline Diabetes mellitus post TxR n (\%) & $11(10,1)$ & $8(11,1)$ & NS \\
\hline Hospitalizaciones durante año 1 del TxR n (\%) & $65(59,1)$ & $41(56,9)$ & NS \\
\hline Hospitalizaciones por infecciones durante 1 er año del TxR n (\%) & $28(25,4)$ & $22(30,6)$ & NS \\
\hline Hospitalizaciones por causa CV durante $1^{\text {er }}$ año del TxR n (\%) & $11(10,0)$ & $2(2,8)$ & NS \\
\hline Proteinuria > 500 mg/día al año del TxR n (\%) & $6(4,6)$ & $4(6,0)$ & NS \\
\hline Hematuria $\geq 5$ eritrocitos $\mathrm{p} / \mathrm{c}$ al año del TxR $\mathrm{n}(\%)$ & $11(10,3)$ & $6(9,1)$ & NS \\
\hline Hospitalizaciones durante años 2-10 del TxR n (\%) & $51(46,4)$ & $32(44,4)$ & NS \\
\hline Hospitalizaciones por infecciones durante años 2-10 del TxR n (\%) & $21(19,1)$ & $12(16,7)$ & NS \\
\hline Hospitalizaciones por causa CV durante años 2-10 del TxR n (\%) & $6(5,4)$ & $5(6,9)$ & NS \\
\hline Proteinuria > 500 mg/día al año 3 del TxR n (\%) & $6(6,4)$ & $8(13,6)$ & NS \\
\hline Hematuria $\geq 5$ eritrocitos $\mathrm{p} / \mathrm{c}$ al año 3 del TxR n (\%) & $9(9,6)$ & $9(15,8)$ & NS \\
\hline Neoplasias malignas primeros 5 años del TxR n (\%) & $6(5,5)$ & $5(6,9)$ & NS \\
\hline Neoplasias malignas años 6-10 post TxR n (\%) & $10(9,6)$ & $8(11,4)$ & NS \\
\hline Varicela/Herpes Zoster durante evolución n (\%) & $17(15,6)$ & $9(12,5)$ & NS \\
\hline Infección por CMV durante evolución n (\%) & $6(5,5)$ & $5(6,9)$ & NS \\
\hline Tuberculosis durante evolución n (\%) & $2(1,8)$ & $3(4,2)$ & NS \\
\hline Necrosis ósea avascular n (\%) & $10(9,2)$ & $4(5,6)$ & NS \\
\hline Fracturas óseas n (\%) & $8(7,3)$ & $4(5,6)$ & NS \\
\hline Artritis gotosa $\mathrm{n}(\%)$ & $10(9,2)$ & $7(9,7)$ & NS \\
\hline Eritrocitosis durante evolución del TxR n (\%) & $12(11,0)$ & $13(18,1)$ & NS \\
\hline Daño hepático crónico n (\%) & $6(5,5)$ & $9(12,5)$ & NS \\
\hline Biopsia renal durante evolución del TxR n (\%) & $44(40,4)$ & $30(41,7)$ & NS \\
\hline
\end{tabular}

TxR: trasplante renal; CV: cardiovasculares.

Tabla 6. Causa de muerte con riñón funcionante en 32 trasplantados renales

\begin{tabular}{|lccc|}
\hline Causa de muerte & $\begin{array}{c}\text { Grupo 0 } \\
(\mathbf{n = 1 4 )}\end{array}$ & $\begin{array}{c}\text { Grupo 1 } \\
(\mathbf{n = 1 8 )}\end{array}$ & p \\
\hline Cáncer n (\%) & $5(36)$ & $2(11)$ & NS \\
\hline Infecciones n (\%) & $5(36)$ & $9(50)$ & NS \\
\hline Digestiva n (\%) & $2(14)$ & $3(17)$ & NS \\
\hline Cardiovascular n (\%) & $2(14)$ & $4(22)$ & NS \\
\hline
\end{tabular}

\section{Discusión}

El incremento de peso después de un TxR es frecuente durante el primer año y diversas series han comunicado variaciones entre 2,7 y 10,3 $\mathrm{kg}^{6,27,28,30,32}$. En esta serie el incremento promedio fue $6,6 \mathrm{~kg}$. Se ha observado que el mayor incremento de peso ocurre en los primeros 6 meses del $\mathrm{TxR}^{29}$.

El aumento de peso posterior al trasplante se 

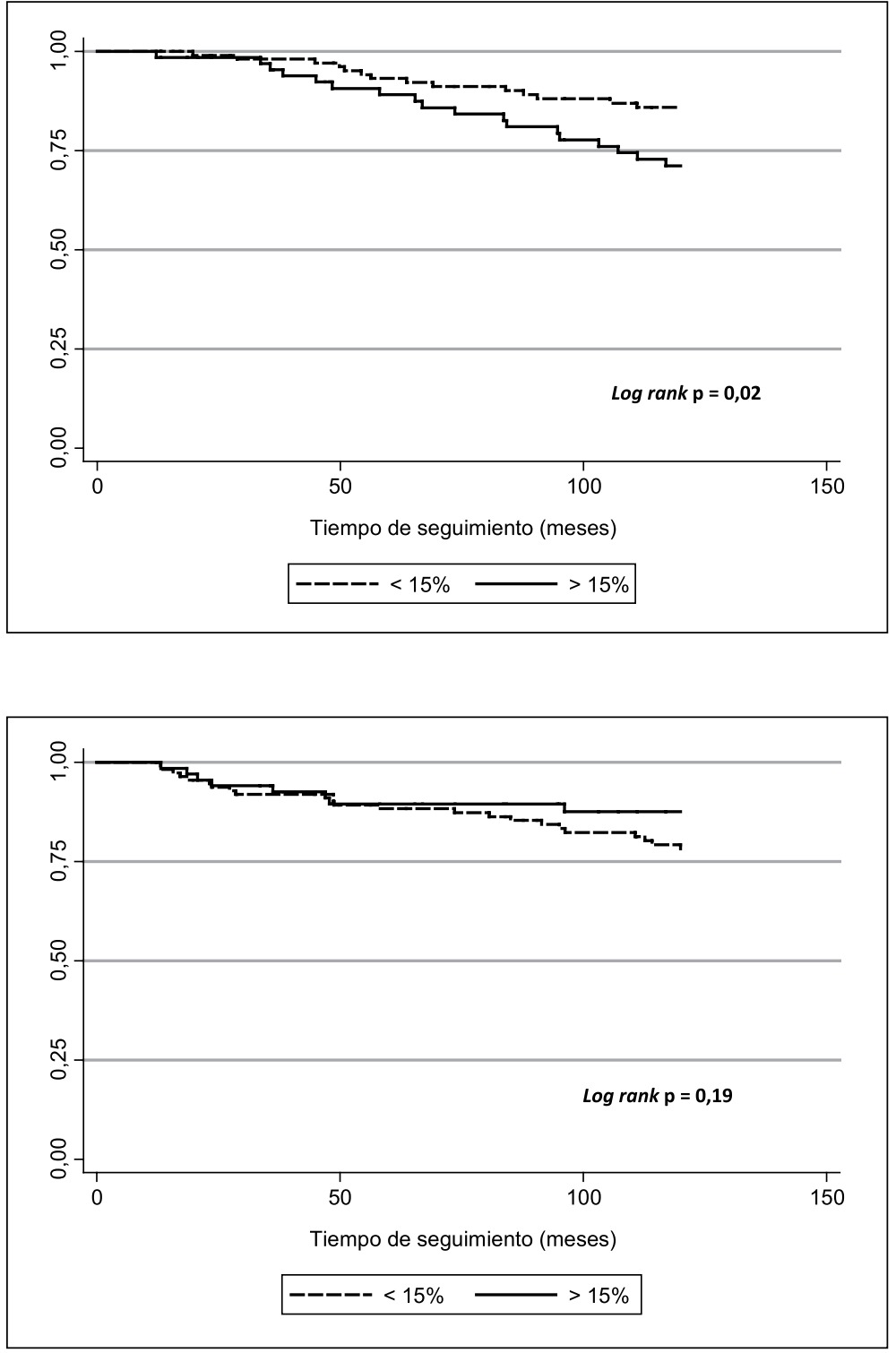

Figura 1. Curva de supervivencia de pacientes según ganancia de peso (Kaplan-Meier).
Figura 2. Curva de supervivencia de injertos según ganancia de peso (Kaplan-Meier). asocia con frecuencia al desarrollo de hipertensión arterial, resistencia a la insulina, síndrome metabólico, diabetes mellitus, hiperlipidemia y enfermedad coronaria ${ }^{6,13,17,29,33,34}$. Todas estas condiciones se han asociado a una mayor mortalidad en la población general.

En un estudio catalán, que incluyó a 2.691 pacientes, al momento del TxR 38\% tenían sobrepeso y $16 \%$ obesidad. De los pacientes que tenían un IMC normal, 26\% desarrollaron sobrepeso y $6 \%$ obesidad. En los que tenían sobrepeso 68\% persistieron con sobrepeso y $16 \%$ se tornaron obesos $^{35}$.

En otro estudio australiano, al momento del TxR 9\% de los pacientes eran obesos y a los 6 meses este porcentaje había aumentado a $30 \%{ }^{36}$.

Un estudio francés que incluyó a 292 trasplantados renales durante un período de 10 años encontró que una proporción significativa de los pacientes incrementaba su peso durante el primer año de $\mathrm{TxR}^{27}$. Al momento de la intervención $77,5 \%$ de ellos tenía un IMC normal, 16,4\% sobre- 
peso y sólo 6,1\% eran obesos. Al año del TxR los porcentajes fueron $70,2 \%, 19,9 \%$ y $9,9 \%$, respectivamente. Los pacientes que incrementaron su IMC en $>5 \%$ al año del TxR tuvieron tres veces más riesgo de perder el injerto durante el seguimiento. La ganancia de peso durante el primer año pudo predecir la pérdida de los injertos independientemente del IMC. Adicionalmente, los pacientes que incrementaron su IMC en $>5 \%$ al año tuvieron más frecuentemente hipertrigliceridemia, C-HDL bajo, hipertensión arterial y diabetes mellitus ${ }^{27}$.

Un estudio australiano-neozelandés, que incluyó 3.899 pacientes trasplantados durante un período de 13 años, encontró que $44 \%$ de los pacientes aumentaron su peso al año en $<10 \%$, $24 \%$ entre $10 \%$ y $19,9 \%$ y $9 \%$ en $\geq 20 \%{ }^{28}$. Estos últimos tuvieron una significativa mayor pérdida de injertos y muerte con riñón funcionante durante el seguimiento. No hubo diferencias en las causas de muerte respecto a los que tuvieron cambios menores en su peso al primer año. Los pacientes con ganancia de peso $\geq 20 \%$ fueron más jóvenes, predominantemente mujeres, tuvieron donantes más jóvenes y no tenían enfermedades cardiovasculares previas al TxR.

Un estudio egipcio, que incluyó a 650 pacientes trasplantados renales durante un período de 15 años con un IMC normal $\left(18,5-25,0 \mathrm{~kg} / \mathrm{m}^{2}\right)$ al momento del TxR, encontró que los pacientes que habían aumentado su IMC a $\geq 30 \mathrm{~kg} / \mathrm{m}^{2}$ a los 6 meses del TxR desarrollaron más frecuentemente diabetes mellitus, hipertensión arterial, hiperlipidemias y enfermedad coronaria. Las pérdidas de injertos y muertes con riñón funcionante a los $5 \mathrm{y}$ 10 años de seguimiento fue significativamente mayor y la función renal inferior a los pacientes que incrementaron su IMC en una menor magnitud ${ }^{29}$.

Otro estudio incluyó a 212 trasplantados renales con injertos funcionantes al año y con un seguimiento promedio de 5 años encontró que los pacientes que incrementaron su IMC $>10 \%$ durante el seguimiento fueron más jóvenes que los que no lo incrementaron en esa magnitud, requirieron mayor terapia antihipertensiva y tuvieron niveles más elevados de C-LDL. No observaron un incremento de la incidencia de eventos cardiovasculares no fatales. En este estudio no comunicaron información sobre las pérdidas de injertos o pacientes ${ }^{30}$.

Un estudio turco, que incluyó a 93 trasplantados con donantes vivos relacionados, encontró que los que incrementaban su IMC $>10 \%$ en forma sostenida durante los 2 primeros años del TxR presentaban más frecuentemente una nefropatía crónica del injerto. Sin embargo, la tasa de pérdidas de injertos durante el seguimiento no tuvo diferencias significativas ${ }^{31}$.

Hoogeveen et al estudiaron 1.810 trasplantados durante un período de 13 años y con un seguimiento promedio de 8,3 años; encontraron que los pacientes que tenían un IMC $>30 \mathrm{~kg} /$ $\mathrm{m}^{2}$ al año del TxR tenían una significativa mayor tasa de pérdidas de injertos y muerte con riñón funcionante durante el seguimiento, respecto a los pacientes con IMC normal. La proporción de pacientes obesos al momento del TxR fue 5,6\% y aumentó a $11,5 \%$ al año del $\mathrm{TxR}^{13}$.

En nuestra serie, los receptores que incrementaron su peso $\geq 15 \%$ durante el primer año no fueron más jóvenes que los que modificaron su peso en una magnitud menor, no tuvieron una mayor frecuencia de eventos cardiovasculares o diabetes mellitus post-trasplante, mayor pérdida de injertos (censurando las muertes) ni una función renal inferior durante los 10 años de seguimiento; como algunas comunicaciones ya mencionadas. Sólo presentaron una mayor frecuencia de muerte con riñón funcionante, aunque las causas de muerte no difirieron del grupo con menor cambio en su peso al año del TxR.

Se ha tratado de relacionar al incremento de peso con la menor sobrevida de injertos y pacientes, así como a la nefropatía crónica del injerto.

El tejido adiposo se reconoce como un órgano inmune que secreta numerosos factores inmunomoduladores como TNF-alfa e IL-6. Se ha sugerido que la obesidad representa un estado inflamatorio de baja intensidad con un rol potencial en la patogénesis y agravación de la hipertensión arterial y la disfunción endotelial ${ }^{37}$. Es frecuente que los pacientes que incrementan su IMC después del TxR tengan una PCR más elevada que los pacientes con IMC normal y que desarrollen hiperinsulinemia y síndrome metabólico ${ }^{34}$. La inflamación de bajo grado puede modular el impacto del síndrome metabólico sobre el injerto ${ }^{27}$.

La hiperinsulinemia puede inducir directamente hipertrofia glomerular o indirectamente a través del estímulo del receptor de IGF-1. También puede interactuar con los niveles intrarenales elevados de angiotensina II, aumentando la contracción de las células mesangiales mediadas por 
angiotensina $\mathrm{II}^{38,39}$. En cultivos de células mesangiales expuestos a altas dosis de insulina se ha observado que aumenta la expresión de colágeno, lo que no es reversible al suspender la exposición a insulina, lo que implica que la exposición a altas concentraciones de insulina origina una transformación genética permanente ${ }^{40}$. Ello sugiere que la ganancia de peso durante el primer año del TxR, con la consecuente hiperinsulinemia, puede tener efectos de largo plazo en la estructura y función del injerto renal ${ }^{27}$.

La obesidad se asocia con un exceso de la carga excretora en relación a la masa corporal, por la ingesta calórica aumentada y el "turnover" tisular, lo que origina dilatación de la arteriola aferente, hiperperfusión, hiperfiltración e hipertensión intraglomerular. Ello puede llevar a glomeruloesclerosis $^{41}$. La hipertensión glomerular es importante porque los trasplantados son monorrenos y hay menos nefrones ${ }^{42}$. La obesidad también aumenta la reabsorción tubular de sodio debido a la activación del sistema simpático y renina-angiotensina-aldosterona. Ello aumenta la velocidad de filtración glomerular en orden a mantener la homeostasis de la sal, lo que origina un aumento de la presión hidrostática glomerular, favoreciendo la glomeruloesclerosis ${ }^{41}$. La hiperlipidemia asociada a la obesidad a través de su interacción con los receptores de LDL en las células mesangiales y el estrés oxidativo favorece la glomeruloesclerosis ${ }^{42}$.

Los niveles patológicos de adipocitokinas pueden originar una nefropatía crónica del injerto en los trasplantados obesos ${ }^{11}$. La leptina, secretada por el tejido adiposo, estimula la expresión de TGF- $\beta$ en el riñón, originando proliferación de células mesangiales y depósito de colágeno, originando proteinuria, favoreciendo la glomeruloesclerosis y la fibrosis renal. El TNF-alfa secretado por los adipocitos promueve la inflamación intrarenal y favorece la glomeruloesclerosis. Otros factores derivados del adipocito, como A II y el inhibidor del activador del plasminógeno I, producen injuria endotelial favoreciendo el daño vascular y la glomeruloesclerosis ${ }^{44-47}$.

Este estudio tiene algunas fortalezas, como el seguimiento prolongado de los pacientes e injertos (10 años) y el obtener los datos de un registro prospectivo de la evolución de todos los pacientes. Las debilidades son el no contar con la información de la altura de los pacientes al momento del trasplante (para calcular el IMC) y el tratarse de pacientes de un solo centro de trasplante, lo que no permite generalizar la información obtenida en esta investigación. Sin embargo, ella corrobora lo encontrado en las comunicaciones de otros centros de trasplante en cuanto que la ganancia significativa de peso post-trasplante se asocia a un riesgo de mayor mortalidad durante el seguimiento.

\section{Referencias}

1. Calle EE, Thun MJ, Petrelli JM, Rodríguez C, Heath CW Jr. Body-mass index and mortality in a prospective cohort of U.S. adults. N Engl J Med 1999; 341: 1097-105.

2. Obesity: Preventing and managing the global epidemic. Report of a WHO consultation. World Health Organ Tech Rep Ser 2000; 894: i-xii 1-253.

3. Byers T. Body weight and mortality. N Engl J Med 1995; 333: 723-4.

4. Friedman AN, Misculin DC, Rosemberg IH, Levey AS. Demographics and trends in overweight and obesity in patients at time of kidney transplantation. Am J Kidney Dis 2003; 41: 480-7.

5. Van den Ham EC, Kooman JP, Christiaans MH, Leunissen KM, van Hooff JP. Posttransplantation weight gain is predominantly due to an increase in body fat mass. Transplantation 2000; 70: 241-3.

6. Clunke JM, Lin CY, Curtis JJ. Variables affecting weight gain in renal transplant recipients. Am J kidney Dis 2001; 38: 349-53.

7. Jurewitz WA, Baboolal K. Obesity and renal transplantation. Transplantation 2002; 74: 600-1.

8. Işiklar I, Akin O, Demirăg A, Niron EA. Effects of renal transplantation on body composition. Tranplant Proc 1998; 30: 831-2.

9. Chang SH, Coates PT, McDonald SP. Effects of body mass index at transplant and outcomes of kidney transplantation. Transplantation 2007; 84: 981-7.

10. Armstrong KA, Campbell SB, Hawley CM, Johnson DW, Isbel NM. Impact of obesity on renal transplant outcomes. Nephrology (Carlton) 2005; 10: 405-13.

11. Gore JL, Pham PT, Danovitch GM, Wilkinson AH, Rosenthal JT, Lipshutz GS, et al. Obesity and outcome following renal transplantation. Am J Transplant 2006; 6: 357-63.

12. Aalten J, Christiaans MH, de Fijter H, Hené R, van der Heijde JH, Roodnat J, et al Transpl Int 2006; 19: 901-7.

13. Hoogeveen EK, Aalten J, Rothman KJ, Roodnat JI, Mallat MJ, Borm G, et al. Effect of obesity on the outcome of kidney transplantation: A 20 year of follow-up. Transplantation 2011; 91: 869-74. 
14. Yamamoto S, Hanley E, Hahn AB, Isenberg A, Singh $\mathrm{TP}$, Cohen D, et al. The impact of obesity in renal transplantation: an analysis of paired cadaver kidneys. Clin Transplant 2002; 16: 252-6.

15. Baum CL, Thielke K, Westin E, Kogan E, Cicalese L, Benedetti E. Predictors of weight gain and cardiovascular risk in a cohort of racially diverse kidney transplant recipients. Nutrition 2002; 18: 139-46.

16. Pischon T, Sharma AM. Obesity as a risk factor in renal transplant patients. Nephrol Dial Transplant 2001; 16: 14-7.

17. de Vries AP, Bakker SJ, van Son WJ, van der Heide JJ, Ploeg RJ, The HT, et al. Metabolic syndrome is associated with impaired long-term renal allograft function; not all component criteria contribute equally. Am J Transplant 2004; 4: 1675-83.

18. Olarte IG, Hawasli A. Kidney transplant complications and obesity. Am J Surg 2009; 197: 424-6.

19. Modlin CS, Flechner SM, Goormastic M, Goldfarb DA, Papajcik D, Mastroianni B, et al. Should obese patients lose weight before receiving a kidney transplant? Transplantation 1997; 64: 599-604.

20. Meier-Kriesche HU, Arndorfer JA, Kaplan B. The impact of body mass index on renal transplant outcomes. A significant independent risk factor for graft failure and patient death. Transplantation 2002; 73: 70-4.

21. Merion RM, Twork AM, Rosenberg L, Ham JM, Burtch GD, Turcotte JG, et al Obesity and renal-transplantation. Surg Gynecol Obstet 1991; 172: 367-76.

22. Mercén R, Fernández A, Pascual J, Teruel JL, Villafruela JJ, Rodríguez N, et al. High body mass index and posttransplant weigh gain are not risk factors for kidney graft and patient outcome. Transplant Proc 2007; 39: 2205-7.

23. Orofino L, Pascual J, Quereda C, Burgos J, Marcen R, Ortuño J. Influence of overweight on survival of kidney transplant. Nephrol Dial Transpl 1997; 12: 855.

24. Johnson DW, Isbel NM, Brown AM, Kay TD, Franzen K, Hawley CM, el al. The effect of obesity on renal transplant outcomes. Transplantation 2002; 74: 67581.

25. Howard RJ, Thai VB, Patton PR, Hemming AW, Reed AI, Van der Werf WJ, et al. Obesity does not portent a bad outcome for kidney transplant patients. Trasplantation 2002; 73: 53-5.

26. Marks WH, Florence LS, Chapman PH, Precht AF, Perkinson DT. Morbid obesity is not a contraindication to kidney transplantation. Am J Surg 2004; 187: 635-8.

27. Ducloux D, Kazory A, Simula-Faivre D, Chalopin JM. One-year post-transplant weigh gain is a risk factor for graft loss. Am J Transpl 2005; 5: 2922-8.
28. Chang SH, McDonald SP. Post-kidney transplant weight change as a marker of poor survival outcomes. Transplantation 2008; 85: 1443-8.

29. el-Agroudy AE, Wafa EW, Gheith OE, Shehab el-Dein $\mathrm{AB}$, Ghoneim MA. Weight gain after renal transplantation is a risk factor for patient and graft outcome. Transplantation 2004; 77: 1381-5.

30. Díaz JM, Sainz Z, Oliver A, Guirado LI, Facundo C, García-Maset R, et al. Post-renal transplantation weight gain: its causes and its consequences. Transpl Proc 2005; 37: 3839-41.

31. Micozkadioglu H, Ozdemir FN, Sezer S, Arat Z, Haberal $\mathrm{M}$. Weight gain after living-related renal transplantation affects long-term graft function. Transpl Proc 2005; 37: 1029-32.

32. Baum CL. Weight gain and cardiovascular risk after organ transplantation. JPEN J Parenter Enteral Nutr 2001; 25: 114-9.

33. Parikh CR, Klem P, Wong R, Yalavarthy R, Chan L. Obesity as an independent predictor of posttransplant diabetes. Transplant Proc 2003; 35: 2922-6.

34. de Alencastro MG, Lemos JR, Bastos NM, Vicari AR, Gonçalves LF, Manfro RC. Evaluation of metabolic syndrome and associations with inflammation and graft function in renal transplant patients. J Bras Nephrol 2013; 35: 299-307.

35. Cofán F, Vela E, Clèries M. Catalan Renal Registry. Obesity in renal Transplantation: analysis of 2691 patients. Transpl Proc 2005; 37: 3695-7.

36. Armstrong KA, Campbell SB, Hawley CM, Nicol DL, Johnson DW, Isbel NM. Obesity is associated with worsening cardiovascular risk factor profiles and proteinuria progression in renal transplant recipients. Am J Transpl 2005; 5: 2710-8.

37. Wisse BE. The inflammatory syndrome: the role of adipose tissue cytokines in metabolic disorders linked to obesity. J Am Soc Nephrol 2004; 15: 2792-800.

38. Abrass CK, Raugi GJ, Gabourel LS, Lovett DH. Insulin and insulin-like growth factor I binding to cultured rat glomerular mesangial cells. Endocrinology 1988; 123: 2432-9.

39. Kreisberg JI. Insulin requirement for contraction of cultured rat glomerular mesangial cells in response to angiotensin II: possible role for insulin in modulating glomerular hemodynamics. Proc Natl Acad Sci USA 1982; 79: 4190-2.

40. Abrass CK, Spicer D, Raugi GJ. Induction of nodular sclerosis by insulin in rat mesangial cells in vitro: studies of collagen. Kidney Int 1995; 47: 25-37.

41. Chagnac A, Weinstein T, Korzets A, Ramadan E, Hirsch J, Gafter U. Glomerular hemodynamic in severe obesity. 
Am J Physiol Nephrol Physiol 2000; 278: F817-22.

42. Praga M, Hernández E, Herrero JC, Morales E, Revilla Y, Díaz-González R, et al. Influence of obesity on the appearance of proteinuria and renal insufficiency after unilateral nephrectomy. Kidney Int 2000; 58: 2111-8.

43. Keane WF. Lipids and the kidney. Kidney Int 1994; 46: 910-20.

44. Wolf G, Hamann A, Han DC, Helmchen U, Thaiss F, Ziyadeh FN, et al. Leptin stimulates proliferation and TGF- $\beta$ expression in renal glomerular endothelial cells: Potential role in glomerulosclerosis. Kidney Int 1999; 56: 860-72.
45. Wolf G, Chen S, Han DC, Ziyadeh FN. Leptin and renal diseases. Am J Kidney Dis 2002; 39: 1-11.

46. Yudkin JS, Stehouwer CD, Emeis JJ, Coppack SW. C-reactive protein in healthy subjects: Associations with obesity, insulin resistance, and endothelial dysfunction: A potential role for cytokines originating from adipose tissue? Arterioscler Thromb Vasc Biol 1999; 19: 972-8.

47. Samad F, Uysal KT, Wiesbrock SM, Pandey M, Hotamisligil GS, Loskutoff DJ. Tumor necrosis factor alpha is a key component in the obesity-linked elevation of plasminogen activator inhibitor 1. Proc Natl Acad Sci 1999; 96: 6902-69. 